\title{
Ajdukiewicz and the Notion of Conceptual Apparatus
}

Prof. Michele Marsonet

University of Genoa, Italy

\section{Abstract}

The Polish philosopher Kazimierz Ajdukiewicz adopted the notion of "conceptual apparatus", which is very similar to the idea of "conceptual scheme" put forward by Donald Davidson, Willard V. Quine, Nicholas Rescher and others. Ajdukiewicz's theses are, in this regard, very important although less known, and he treated cognitive processes as inseparably connected with language.

Keywords: language; conceptual apparatus; conceptual scheme; ontology; empiricism.

\section{Introduction}

Kazimierz Ajdukiewicz (1890-1963) is one of the main representatives of the famous "Polish logical-philosophical school", which is close to the logical empiricists of the Vienna and Berlin circles. He wrote many celebrated essays on philosophy of language, logic, philosophy of logic, metaphysics and epistemology. Ajdukiewicz, particularly in the 1930's and 1940's, anticipated many theses subsequently put forward by such authors as Willard V. Quine, Donald Davidson and Nicholas Rescher, with particular reference to the topic of "conceptual schemes".

\section{Ajdukiewicz and the autonomy of language}

Ajdukiewicz always insists on the autonomy of language which, in his view, determines our world-view. When the Communist Party went to power in Poland with the aid of Soviet Union's Red Army, many Marxist Polish philosophers bitterly attacked Ajdukiewicz. They accused him of overvaluing the role of language and of being, thus, an idealist. He replied that such charges were false, but had many problems in the Polish philosophical environment of that time, which was dominated by orthodox Marxist thinkers.

It's weird to note that, when one gets involved in the contemporary debate on conceptual schemes, he very rarely finds mention of Kazimierz Ajdukiewicz. ${ }^{1}$ However, the theses of the Polish philosopher in this regard are quite important, and we deem his contribution to be no less original - and no less controversial - than those of Quine, Davidson and Rorty. Let us note from the onset that even for Ajdukiewicz conceptual schemes are languages. Furthermore, we would like to point out that Ajdukiewicz

${ }^{1}$ With the exception, of course, of such texts dealing specifically with Polish philosophy of the past century such as [Skolimowski 1967] and [Wolenski 1989]. 
wrote his main essays on this topic in the 1930's, i.e. half a century before the debate on conceptual schemes started following the publication of Davidson's paper in 1974. This confirms, we believe, the originality of his approach. Wolenski rightly notes that Ajdukiewicz's approach is linguistic all the way down, and that he devised no evolutionary structure in language. But this, of course, is no reason for denying the importance of his theses for the contemporary debate: Ajdukiewicz's limits, after all, are the limits of analytic philosophy itself.

Jan Wolenski writes in this regard that "Ajdukiewicz treated cognitive processes as inseparably connected with language: we always think in some language, and our statements are meanings which are attributes of sentences in some language L. Hence cognition, or, to put it more rigorously, cognition as a product, can be identified with the meaning of sentences. This is the essential methodological intention of Ajdukiewicz's semantic epistemology". ${ }^{2}$ In the Polish philosopher's works the expression "conceptual apparatus" replaces "conceptual scheme".

\section{Ajdukiewicz's notion of conceptual apparatus}

Ajdukiewicz's notion of conceptual apparatus is strictly tied to close and connected languages, and thus has a more technical connotation than what is meant today by the expression "conceptual scheme". Wolenski tells us that "the class of meanings of a closed and connected language was termed by Ajdukiewicz the conceptual apparatus of that language. It follows from the appropriate definitions that two conceptual apparatuses are either identical or have no element in common. And a consequence $[\ldots]$ is that if two conceptual apparatuses have at least one element in common, then they are identical. Thus conceptual apparatuses never overlap. Ajdukiewicz held that every meaning belongs to some conceptual apparatus. Hence open languages are mixtures of various conceptual apparatuses". ${ }^{3}$

Let us note, at this point, that Ajdukiewicz's theses are subject to the same criticisms we previously addressed to Davidson and Rorty. Laudan's remark that only a full endorsement of the linguistic turn's main tenets may explain why so many philosophers insist on equating conceptual schemehood to languagehood apply to Ajdukiewicz as well. Only now, following the rise of post-analytic philosophy and the rediscovery of pragmatism, the basic tenet according to which linguistic behavior is the sole behavior that really matters has openly been challenged. ${ }^{4}$ We all know, of course, that Ajdukiewicz's conception of language is an autonomous one, since he took language to be a product which is independent of action. Wolenski reminds us that "[...] the problem is clarified immediately when we consider the fact that Ajdukiewicz was not

\footnotetext{
2 [Wolenski 1989], p. 199.

${ }^{3}$ Ibid., pp. 204-205.

${ }^{4}$ See for example [Devitt 1991] and N. Rescher, "The Rise and Fall of Analytic Philosophy", in [Rescher 1994], pp. 31-42.
} 
interested in the origins of a language, but in language as a product. The thesis on the autonomy of language acquires meaning when we bear in mind the difference between actions and their products (taken over by Ajdukiewicz from Twardowski). An objective assignment of meanings to expressions is possible only when language is treated as a product". ${ }^{5}$

\section{Ajdukiewicz's radical conventionalism}

Yet, this fact does not distinguish Ajdukiewicz's ideas from the main stream of the linguistic philosophy of our century. What makes Ajdukiewicz's thought so appealing is the fact that he cleverly anticipated, in the 1930's, many theses that are commonly discussed today. So we find out that his "radical conventionalism", despite its several shortcomings, has many precious insights too, because in a famous paper dating back to 1934 he wrote: "Of all the judgements which we accept and which accordingly constitute our entire world-picture, none is unambiguously determined by experimental data; every one of them depends on the conceptual apparatus we choose to use in representing experiential data. We can choose, however, one or another conceptual apparatus which will affect our whole world picture". ${ }^{6}$

Subsequently Quine became famous for saying more or less the same thing, while Ajdukiewicz's contributions are still ignored by most Western philosophers. Quine remarks that there are many implicit background assumptions which make all the difference to how we interpret our experiences, and how we make our final evaluation of statements. This means that we cannot simply get meaning from experience, since there are no "neutral" observations available to men. And it is precisely because our conceptual judgements meet experience as a body that we must allow for possible revisions at any place within that body, so that "no statement is immune to revision".7 And, if this is right, we must even allow for the possibility of changes in our verdicts on what is experienced itself.

Compare Quine's statements with the following by Ajdukiewicz: "No articulated judgement is absolutely forced on us by the data of experience. Experiential data do indeed force us to accept certain judgments if also we are based on a particular conceptual apparatus. However, if we change this conceptual apparatus, we are freed of the necessity of accepting these judgments despite the presence of the same experiential data". ${ }^{8}$ It is clear that what Quine defines as our "conceptual sovereignty" plays a key role even in this context, although the words used by the two authors are not the same. In any event, the striking similarity between the two philosophers is

\footnotetext{
${ }^{5}$ [Wolenski 1989], p. 205.

${ }^{6}$ K. Ajdukiewicz, "The World-Picture and the Conceptual Apparatus", in [Ajdukiewicz 1978], p. 67.

${ }^{7}$ V.V. Quine, "Two Dogmas of Empiricism", in [Quine 1980], p.43.

${ }^{8}$ K. Ajdukiewicz, ibid., p. 72.
} 
clearly detectable, once again, in the following statements by Ajdukiewicz (written in 1935): "Even the epistemologist cannot speak without a language, cannot think without a conceptual apparatus. He will thus make his decision as to truth in a way which corresponds to his world-perspective". ${ }^{9}$

Not only that: even logic is, according to the Polish philosopher, "relative to" a particular conceptual apparatus, and a change in the conceptual apparatus means a change in logic, too. ${ }^{10}$ On his part, Quine claims that "revision even of the logical law of the excluded middle has been proposed as a means of simplifying quantum mechanics; and what difference is there in principle between such a shift and the shift whereby Kepler superseded Ptolemy, or Einstein Newton, or Darwin Aristotle?". ${ }^{11}$

\section{Bibliography}

1. K. Ajdukiewicz, The Scientific World-Perspective and Other Essays, 1931-1963, Dordrecht, Reidel, 1978.

2. D. Davidson, Inquiries into Truth and Interpretation, Oxford, Clarendon Press, 1984.

3. M. Devitt, Realism and Truth, Oxford, Blackwell, 2nd ed., 1991.

4. Marsonet, Michele. "Rorty on Language and Social Practices." Academicus International Scientific Journal 10 (2014): 30-38.

5. Marsonet, Michele. "Philosophy and logical positivism." Academicus International Scientific Journal 10.19 (2019): 32-36.

6. Marsonet, Michele. "Quine on the Dogmas of Empiricism." Academicus International Scientific Journal 10.20 (2019): 93-105.

7. W.V. Quine, From a Logical Point of View, Cambridge (Mass.), Harvard University Press, 2nd ed., 1980.

8. N. Rescher, American Philosophy Today and Other Philosophical Studies, Lanham, Rowman \& Littlefield, 1994.

9. H. Skolimowski, Polish Analytic Philosophy, London, Routledge \& Kegan Paul, 1967.

10. J. Wolenski, Logic and Philosophy in the Lvov-Warsaw School, Dordrecht, Kluwer, 1989.

\footnotetext{
${ }^{9}$ K. Ajdukiewicz, "The Scientific World-Perspective", in [Ajdukiewicz 1978], p. 117.

${ }^{10}$ [Wolenski 1989], p. 208.

${ }^{11}$ W.V. Quine, "Two Dogmas of Empiricism", cit., p. 43.
} 